\title{
Produsage: produção de conhecimento, democratização da cultura e colaboração mediada por tecnologias em rede
}

\author{
Elena Maria Mallmann'
}

BRUNS, Axel. Blogs, Wikipedia, Second Life, and beyond: from production to produsage. New York: Peter Lang Publishing, 2008.

Como analisar criticamente os processos de produção, distribuição e consumo de produtos e conteúdo intelectual na contemporaneidade industrial globalizada? No livro Blogs, Wikipedia, Second Life, and beyond: from production to produsage, o australiano Axel Bruns constrói argumentos que sustentam a tese centrada na produsage. $\mathrm{O}$ autor defende que a produsage é um modelo alternativo de produção e circulação do conhecimento, criatividade, democratização da cultura e colaboração mediada pelas tecnologias em rede. O livro é resultado das pesquisas desenvolvidas na Queensland University of Technology, em Brisbane, na University of Leeds e no Massachusetts Institute of Technology (MIT), e sua discussão conceitual é mesclada com exemplos de aplicações práticas. A contribuição singular dessa obra para os estudos em educação é a análise crítica sobre os modos de produção, distribuição e consumo tendo em vista questões econômicas, culturais e legais da criação, compartilhamento, acesso, reutilização e reformulação de conteúdos digitais. Bruns (2008) discorre que o $\mathrm{C}$ da Geração $\mathrm{C}$ está relacionado à content, mas também à creativity, casual collapse, control e celebrity. Em contraste aos modelos tradicionais de produção industrial, produsage refere-se aos processos criativos e de inovação descentralizada na produção de conteúdos liderada pelos participantes nas redes.

Bruns organizou a obra em 418 páginas distribuídas em quinze capítulos que tratam dos seguintes conteúdos:

1. Introdução e contexto da produsage

2. Características-chave da produsage

3. Contribuições equipotenciais do movimento Free Software e Open Source

4. Colaboração em blogs e novos espaços para o jornalismo

5 e 6. Criação, distribuição, crítica e acreditação na Wikipedia

'Universidade Federal de Santa Maria, Santa Maria, Rio Grande do Sul, Brasil. 
7 e 8. Estruturas de indexação em folksonomies e taxonomies

9. Criatividade distribuída em textos, imagens, vídeos e música

10. Criação industrial e copyright

11. Games e Second Life

12. Redes sociais

13. Educação e competências na produsage

14. Democratização e políticas de produsage

15. Conclusões e perspectivas da produsage

Em tempos de impressão doméstica 3D e produção de conteúdos inéditos em situações de alto risco, apoiada por Veículos Aéreos não Tripulados (VANTs)), o livro de Bruns incrementa a composição de reflexões críticas a respeito do universo hipermidiático contemporâneo, então permeado pela efemeridade tecnológica e pela "internet das coisas". Produsage vem da composição hibrida das palavras "production/producters" " "usage/users" e refere-se aos eventos coletivos de produção/distribuição. O debate sociocultural e a pesquisa científica acerca da produção industrial em massa, da liberdade de expressão, direitos autorais, condições de trabalho e exposição midiática são necessários na educação para que se compreendam os impactos da tecnologia na formação e produção da humanidade. Bruns destaca que a produção histórica da existência tem sido sempre transversalizada pelas tecnologias e, atualmente, pelos modos como habitamos e construímos o ciberespaço. O desafio para a leitura do texto se faz importante na medida em que nos oferece bases teóricas pautadas no conceito de produsage para analisar a realidade contemporânea, esta marcada cada vez mais pela comunicação em massa, bem como pela necessidade de transformação da informação em conhecimento.

Segundo Bruns, as redes sociais têm se tornado ambientes de produsage, o que é possível graças ao avanço da web 1.0, que nos anos de 1990 era baseada em leitura de informação (distribuição e consumo), para web 2.0 e 3.0, com mecanismos de metadados, busca, edição, curadoria de conteúdo, feedback, comunicação síncrona e assíncrona many-to-many, upload, jogos eletrônicos, avaliação peer-to-peer (P2P), e-commerce, e-learning e data mining. $\mathrm{O}$ autor ainda destaca exemplos de aplicativos on-line de gerenciamento e compartilhamento, plataformas de edição em fóruns, avatares, a blogsfera, galerias de imagens como Flickr, entretenimento, games, podcasts e músicas, tais como ccMixter, além de páginas Wikipedia, de redes sociais, que podem ser citados MySpace, LinkedIn, Orkut,Facebook, e iniciativas para criação e compartilhamento de mídias pessoais, como OurMedia e canais de vídeo do Youtube. Esses são alguns expoentes da produsage, otimizada pela convergência em aparelhos móveis como tablets e smartphones. Podemos continuamente complementar com exemplos, como iTunes, Twitter, Instagram, WhatsApp, Uber e aplicativos Google, como Maps, Gmail, Drive, Fotos, Hangouts, G+, Tradutor, entre outros.

A obra de Bruns se diferencia de outras que sistematizam entendimentos acerca da maneira como a web 2.0 atua sobre o coletivo ao contrapor as características da produsage ao modelo de produção industrial tradicional. Para o autor, nesse modelo há uma clara separação entre quem produz, distribui e efetivamente consome os resultados do trabalho (produtos físicos ou conteúdo intelectual). Com base na produção de Eric Von Hippel a respeito da democratização da inovação, Bruns argumenta que, mesmo nas situações em que os consumidores podem escolher entre diferentes produtores $\mathrm{e}$ 
distribuidores (influenciados, por exemplo, pelos preços), os modelos produtivos com foco na eficiência e na produtividade, como o taylorista e o fordista, são centrados na hierarquia de produção que sugere a passividade dos usuários e consumidores.

O modelo produsage implica a cultura da participação, que, segundo Herny Jenkins, está desdobrada em competências impulsionadas pela colaboração no desenvolvimento e no compartilhamento de conteúdos e recursos entre pessoas que possuem interesses, necessidades e urgências em comum. Para tanto, é necessário criar ambientes nos quais cada um é livre para contribuir com aquilo que mais conhece e considera adequado em cada contexto.

Produsage é, portanto, um modelo de produção centrado na criatividade disruptiva e ubíqua. Bruns, no capítulo 2 , sinaliza quatro grupos de características-chave da produsage:

1. participação aberta, avaliação comunitária (open participation, communal evaluation);

2. organização equipotencial, não hierárquica (fluid heterarchy, Ad Hoc Meritocracy);

3. artefatos em constante desenvolvimento, processos contínuos (unfinished artefacts, continuing process);

4. propriedade pública, satisfação individual (common property, individual rewards).

Segundo o autor, isso modifica a lógica top-down (direcionado por tarefas) para uma lógica bottom-up (projetos coletivos em que cada participante contribui de acordo com sua expertise). São características com impactos tanto no âmbito da cultura quanto da política e da educação, ambas carecendo de ser estudadas.

Princípios como o da granularidade (tarefas sem denominação quantitativa de participações), com compartilhamento livre e aberto, geram como resultado conteúdos não proprietários que mesclam, hibridizam a produção e a reutilização. A produsage é um movimento contínuo pautado pelas affordances de um framework não centrado na meritocracia porque é um modelo que aumenta o poder de contribuição de todos em rede. Desse modo, o foco da produsage não é a divisão de tarefas, uma vez que há lideranças e especialistas em projetos coletivos desenvolvidos em fluxo contínuo e flexível para avaliação, reutilização e reformulações. Essa abordagem é inovadora e pouco difundida no campo da educação, especialmente na seara das produções didáticas quando articuladas ao sistema de proteção copyright.

Compreendemos que o modelo produsage sustenta e incrementa os princípios basilares do movimento internacional em torno dos recursos educacionais abertos (REA), alicerçados em licenças flexíveis e permissivas, como as oferecidas pelo Creative Commons, e de práticas educacionais abertas alavancas por dominio público, portais governamentais e pelo próprio MIT, tais como a realização dos Massive Open Online Courses (MOOC). Também as discussões sobre esses temas são incipientes na educação, embora cada vez mais emergentes, inclusive nas políticas públicas, o que vale citar como exemplo o Plano Nacional de Educação (PNE). Nessa linha de raciocínio, a discussão sobre produsage repercute claramente no campo teórico-prático da educação mediada pelas tecnologias em rede.

Bruns dedica um capítulo especialmente para tratar da educação dos "produsers" enfatizando a necessidade de professores e estudantes estarem engajados em movimentos pedagógicos que lancem mão de competências como leitura crítica, 
entendimento das especificidades dos modelos de produção para o contexto contemporâneo com cinco capacidades denominadas C5C: criatividade, colaboração, crítica, combinação e comunicação.

A obra resenhada não esgota as sistematizações teóricas a respeito das relações e processos de produção de artefatos e conhecimento no contexto da mediação tecnológica nem dos condicionantes e desdobramentos na educação. Entretanto, as contribuições do texto de Bruns para o debate sociocultural e político educacional destacam o modelo produsage como produção colaborativa de conhecimento e democratização da cultura. Essa proposição teórica sobre modelo de colaboração, criatividade e inovação em rede é essencial para se compreender a repercussão do desenvolvimento tecnológico nos sistemas midiáticos, na economia, políticas públicas, práticas sociais, culturais, educacionais e na própria democracia. As decisões e as ações éticas e estéticas no movimento produtivo em rede exigem participação crítica para a cidadania, isto é, operações de interatividade e interação concretas para desmitificar o modelo tradicional de distribuição e consumo e tornar-se coprodutor de conhecimento. Portanto, estudar o livro de Bruns é emergente para pesquisadores e educadores em tempos da presença incondicional dos aparatos eletrônicos em rede nas salas de aula tanto na educação básica quanto no ensino superior.

\section{REFERÊNCIA}

Bruns, Axel. Blogs, Wikipedia, Second Life, and beyond: from production to produsage. New York: Peter Lang Publishing, 2008.

\section{SOBRE A AUTORA}

Elena Maria Mallmann é doutora em educação pela Universidade Federal de Santa Catarina (UFSC). Professora da Universidade Federal de Santa Maria (UFSM).

E-mail: elena.ufsm@gmail.com

Recebido em 25 de fevereiro de 2017 Aprovado em 5 de julho de 2017 